\title{
Chapter 26: Unleashing the Transformative Power of Learning Analytics
}

\author{
Linda L. Baer ${ }^{1}$, Donald M. Norris ${ }^{2}$ \\ 'Senior Fellow, Civitas Learning, USA \\ ${ }^{2}$ President, Strategic Initiatives, Inc., USA \\ DOI: 10.18608/hla17.026
}

\begin{abstract}
Learning analytics holds the potential to transform the way we learn, work, and live our lives. To achieve its potential, learning analytics must be clearly defined, embedded in institutional processes and practices, and incorporated into institutional student success strategies. This paper explains both the interconnected concepts of learning analytics and the organizational practices that it supports. We describe how learning analytics practices are currently being embedded in institutional systems and practices. The embedding processes include changing the dimensions of organizational culture, changing the organizational capacity and context, crafting strategies for student success, and executing change management plans for student success. These embedding processes can dramatically accelerate the improvement of student success at institutions. The paper includes some institutional success stories and instructive failures. For institutions seeking to unleash the transformative power of learning analytics, the key is an aggressive combination of leadership, active strategy, and change management.
\end{abstract}

Keywords: Learning transformation, $21^{\text {st }}$ century skills, change management, competence building, employment skills, predictive learning analytics, personalized learning

Some keen observers of higher education profess that learning analytics-based practices hold the potential to transform traditional learning (Ali, Rajan, \& Ratliff, 2016). They can also transform competence building that focuses on skills for employment (Weiss, 2014). The combination of predictive learning analytics, personalized learning, learning management systems, and effective linkages to career and workforce knowledge can dramatically shape the manner in which we prepare for and live our lives. Learning analytics will be a linchpin in this multifaceted transformation.

Across the higher education landscape, learning analytics practices are growing. Individual faculty, learning analytics experiments, innovations, and pilot projects - the academic innovation equivalent of "1,000 points of light" - are demonstrating the value of learning analytics in practice (Sclater, Peasgood, \& Mullan, 2016, p. 15). Faculty are building experience in deploying and improving learning analytics practices and sharing their knowledge with their colleagues.
Groups like the Bill \& Melinda Gates Foundation have actively sponsored so-called "next gen" learning projects to advance such efforts. ${ }^{1}$ When they prove their success, these innovations are being nurtured to evolve into full-blown institutional initiatives. Collaborative efforts like the Open Academic Analytics Initiative (OAAI) has developed and deployed an open-source academic early-alert system that can predict (with 70-80\% accuracy) within the first 2-3 weeks of a term which students in a course are unlikely to complete the course successfully (Little et al., 2015). Eventually, such innovations may spread across the higher education and knowledge industry.

Learning analytics practices are also shaping a new generation of academic technology infrastructure. Literally every enterprise resource planning (ERP) and learning management systems (LMSs) vendor is embedding analytics in its products and services

1 See Next Generation Learning Challenge: http://www.educause. edu/focus-areas-and-initiatives/teaching-and-learning/next-generation-learning-challenges 


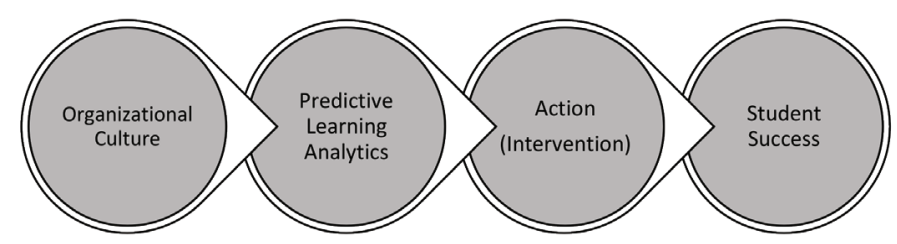

Figure 26.1. Position of predictive learning analytics in the path of student success.

(Baer \& Norris, 2015). Consortia like UNIZIN (Hilton, 2014) have emerged to develop an in-the-cloud, next generation digital learning environment (NGDLE) that can accommodate loosely coupled learning applications, learning object repositories, personalized learning, and analytics capabilities. Learning analytics is a key issue in next gen technology infrastructures and processes.

Clearly, the elements of ubiquitous, predictive learning analytics are coalescing. Practitioners are striving to understand their meaning and how to leverage their impact. Individual faculty and staff, institutional leaders, policy makers, and employers all face different opportunities and challenges in confronting the emergence of learning analytics. In our work with institutions, we have confronted the following questions from various stakeholder groups and individual practitioners:

- How can individual faculty become accomplished learning analytics practitioners, building their expertise and elevating learning analytics practice, across courses and majors, among their peers and across their institution?

- How can institutional faculty and staff involved with student success initiatives embed learning analytics to support dynamic interventions and actions?

- How can institutional leaders and policy makers develop supportive policies, practices, and learning/course management tools that unleash the transformative power of learning analytics across their institutions and beyond?

- How can employers and policy makers provide effective linkages to career and workforce knowledge that will further enhance and extend student success to include academic, co-curricular development, employability, and career elements?

This chapter will help illuminate these opportunities and challenges and provide the context for enabling each of these different stakeholders to understand how to capitalize on the potential of learning analytics.

\section{EMBEDDING LEARNING ANALYT- ICS IN INSTITUTIONAL SYSTEMS, PRACTICES, AND STUDENT SUCCESS STRATEGIES}

In The Predictive Learning Analytics Revolution, the ECAR-Analytics Working Group developed a highly simplified model of the student success process (Little et al., 2015) illustrated in Figure 26.1. It features the central position of predictive learning analytics and action/intervention in the middle of the student learning process. Analytics is essential to informed action/intervention. Without action, analytics is merely reporting; and without an analytics-based foundation, interventions are actions shaped imperfectly by instinct and belief. Enhancing student success depends on this progression of predictive learning analytics to action, all in the context of organizational culture.

The ECAR-Analytics Working Group goes on to stipulate that "before deploying predictive learning analytics solutions, an institution should ensure that its organizational culture understands and values data-informed decision making processes. Equally important is that the organization be prepared with the policies, procedures and skills needed to use the predictive learning analytics tools and be able to distill actionable intelligence from their use" (Little et al., 2015, p. 3).

\section{Changing the Dimensions of Organiza- tional Culture}

This is a laudable prescription. However, our experience with many institutions suggests that even when student success initiatives are thoughtfully launched, organizational culture does not change rapidly, or all at once. In reality, student success initiatives are characterized by the continuous, parallel evolution of organizational culture, organizational capacity, and specific student success projects and actions. Such campaigns often require five to seven years of implementation before yielding substantial organizational change results (Norris \& Baer, 2013). Moreover, understanding the dimensions of the change needed can shift over time; as well, institutional teams, through experience and reflection, develop a better understanding of analytics-enabled student success interventions in practice. 
Table 26.1. Changing Organizational Culture for Student Success in the $21^{\text {st }}$ Century

\begin{tabular}{ccc}
\hline Dimension Of Culture & Traditional Institutional Culture & Transformed Institutional Culture \\
\hline $\begin{array}{c}\text { Use of Data in Decision } \\
\text { Making }\end{array}$ & Culture of Reporting & $\begin{array}{c}\text { Culture of Evidence/Performance } \\
\text { Imperative of Knowing }\end{array}$ \\
\hline Innovation & 1,000 Points of Light & $\begin{array}{c}\text { Successful Innovations are Taken to } \\
\text { Scale }\end{array}$ \\
\hline Collaboration & Individual Faculty Autonomy & $\begin{array}{c}\text { Student Success is Everyone's Job } \\
\text { Community of Practice }\end{array}$ \\
\hline Scope of Student Success & Academic Achievent and Develop- \\
ment & $\begin{array}{c}\text { Fully Integrated Success Assessment: } \\
\text { Academic/Curricular Achievent, } \\
\text { Co-Curricular Development, Work-Re- } \\
\text { lated Experiences, DIY Competence } \\
\text { Building, and Other Elements }\end{array}$ \\
\hline
\end{tabular}

As President Miyares of University of Maryland University College points out, "Often absent from the dialogue is an acknowledgment of the heavy lifting required to leverage analytics as a strategic enabler to transform an institution. There is no 'easy button' for improving the financial, educational, and operational outcomes across an institutional enterprise. Doing so requires a combined commitment of technology, talent, and time to help high-performing colleges and universities leverage analytics not only for one-time insights but also for ongoing performance management and improvement guided by evidence-based decision making" (Miyares \& Catalano, 2016).

Table 26.1 illustrates this point. The first dimension of cultural change needed to enable predictive learning analytics-based interventions for student success involves the use of data in decision making. Institutions must change from a culture of reporting - with no imperative to action - to a culture of performance-based evidence and a commitment to action. This dimension is obvious to most new student success teams. But it takes time and experience with new approaches for the change to take hold and become an embedded practice.

The second and third dimensions of culture change innovation and collaboration - are also critical. Most institutions of higher education support innovations with a lower case "I," leaving them up to individual faculty and celebrating 1,000 points of light. But for student success initiatives to be optimized across the institution they must practice Innovation with a "capital I." They must learn how to take successful innovations and interventions to scale, building on success, and achieving consistency in responses and interventions (Norris \& Keehn, 2003). The traditional collaboration culture is based on individual faculty autonomy, which reinforces the individual innovation culture. Optimizing student success requires greater collaboration, not only among and between faculty, but involving academic support and administrative staff and cross-disciplinary perspectives. Institutions with the most successful student success initiatives (ECAR, 2015) make student success everyone's job, and dramatically increase the network of supporting and intervening persons across the institution. This can include forming active communities of practice dealing with student success.

The fourth dimension of cultural change involves the scope of student success. While traditionally student success focuses on academic achievement, a $21^{\text {st }}$ century transformed perspective on student success scope expands to include an integrated perspective of academic/curricular achievement, co-curricular development, work-related experiences, and do-ityourself (DIY) competence building. The transformation of this fourth dimension is developing more slowly than the first three, but it will accelerate when new mechanisms emerge to share workforce competence knowledge and integrate records of learner's demonstrated learning and competences.

\section{Changing Organizational Context/Capac- ity}

It's not just about culture; it's about all aspects of organizational capacity for analytics and student success initiatives. Table 26.2 portrays the five dimensions of organizational capacity, assessed for a sample institution. Institutional teams that undertake enhancing or optimizing student success and making it an institutional priority have found it useful to assess the current state of capacity development (also called a readiness/maturity index), then establish the targets needed to enhance student success over a reasonable planning period, say five years. Table 26.2 illustrates the current capacity score, the targeted score in five years, and the "gap" between the two that needs to be closed over time (the black bars in the "Target Score" column). Institutional leaders need to focus on setting stretch goals for student success capacity that will position them to meet their targets.

The Community College Research Center (CCRC) studied five Integrated Planning and Advising Services (IPAS) 
Table 26.2. Institutional Context/Capacity for Analytics and Student Success, Current and Targeted

\section{Leadership}

1. Top management is committed to enhancing student success and views predictive learning analytics as essential to student success

2. Analytics has a senior-level champion who can remove barriers, champion funding

3. Top leadership is committed to and consistently practices evidence-based decision making

4. Appropriate funding and investment has been made in analytics, iPASS, ${ }^{*}$ and student success

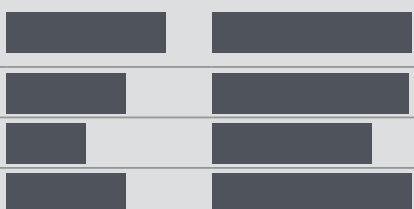

Culture/Behaviour

1. Our institution's culture favours performance-based evidence for decision making

2. Our culture recognizes "the imperative of knowing" and we practice "action analytics"

3. We assess student learning and success innovations and take successful innovations to scale

4. We emphasize collaboration in student success efforts and make student success everyone's job

5. We define and integrate student success to include curricular, co-curricular, work, and talent development

Technology Infrastructure/Tools/Applications

1. Capacity to: Store/access disparate data in raw/transformed form

Store/access predictive results

Deploy/measure the effects of learning interventions

Integrate numerous predictive analytics tools

2. Computing power for regular big data analyses, simulations, visualizations, and processes

3. Security protocols in place to ensure learning analytics effort is not a liability

4. Data governance yields adequate data quality

5. Integrate and unify data sources

6. Adequate iPASS Infrastructure to support analytics-driven interventions

Policies, Processes, and Practices

1. Institutional policies and data stewardship fulfill federal, state, and local laws

2. Workflows for student success processes are well documented

3. Guiding coalition and cross-disciplinary teams for student success

4. Fully integrated planning, resourcing, execution, and communication (PREC) for

student success (eliminates fragmentation - "connects the dots")

\section{Skills and Talent Development}

1. Student success innovation/collaboration skills

2. Specific LA Skills: Data Science: Data analysis, interpretation and visualization

Programming/Vendor product for data mining

Data Literacy - necessary for predictive models/algorithms

Research expertise and understanding of nuanced data

Intervention - time, frequency, tone, and nature

Instructional Design - for embedded predictive analytics

3. Capacity for reinvention of student life cycle processes (end-to-end) is well developed
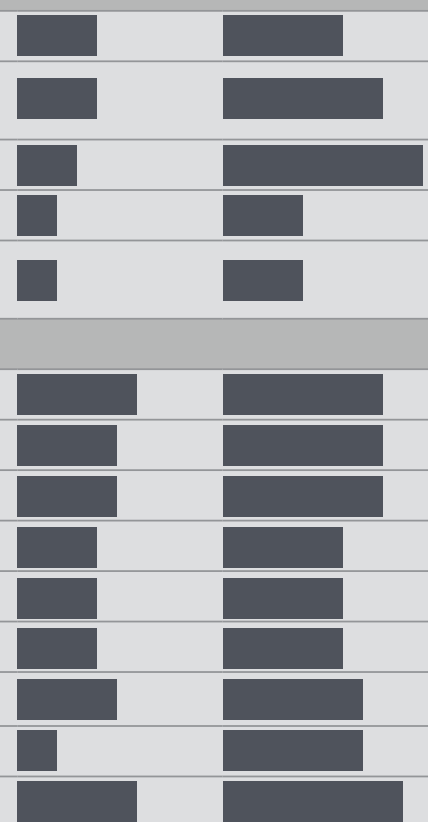

\begin{tabular}{l} 
Programming/Vendor product for data mining \\
\hline Data Literacy - necessary for predictive models/algorithms \\
\hline Research expertise and understanding of nuanced data \\
\hline Intervention - time, frequency, tone, and nature \\
\hline Instructional Design - for embedded predictive analytics \\
\hline 3. Capacity for reinvention of student life cycle processes (end-to-end) is well developed \\
\hline
\end{tabular}

Legend: 1. Initial; 2. Emerging; 3. Functional; 4. Highly Functional; 5. Exemplary

Source: Adapted from the Norris/Baer framework, ECAR Maturity Index, ECAR-Analytics Working Group, \& Educause Maturity and Deployment Indices (Dahlstrom, 2016).

* Individual planning and advising for student success (iPASS) systems combine student planning tools, institutional tools, and student services. iPASS "gives students and administrators the data and information they need to plot a course toward a credential or degree, along with the ongoing assessment and nudges necessary to stay on course toward graduation. iPASS combines advising, degree planning, alerts, and interventions to help students navigate the path toward a credential. These tools draw on predictive analytics to help counselors and advisors determine in advance whether a student is at risk of dropping out or failing out and it can help assist in selecting courses" (Yanosky \& Brooks, 2013). iPASS, used in conjunction with the LMS, is emerging as a key mechanism for delivering the analytics-informed interventions that are proving critical to student success. 
participants to determine readiness for technology adoption (RTA). The RTA framework "is particularly focused on ensuring that technology-based reforms lead to end-user adoption and changed practice" (Karp \& Fletcher, 2014, p. 13). For this to occur, colleges must not only have sufficient technological resources, they must also attend to the cultural components of readiness. Notably, the framework acknowledges the existence of various micro-cultures within an organization - groups of individuals, each with their own culture, norms, and attitudes toward technology (see Karp \& Fletcher, 2014).

\section{Crafting Strategies for Student Success}

Strategy is focused, consistent behaviour over time, responding to ongoing changes in the environment (Mintzberg, Ahlstrand, \& Lampel, 1998). In order to unleash the transformative power of learning analytics, institutions should craft and execute active strategies that enhance student success. These strategies become the mechanism for enhancing capacity and focusing attention on the strategic intent of enhancing student success. Active strategies achieve four outcomes: 1) set direction, 2) focus effort, 3) define the organization, and 4) provide consistency (Baer \& Norris, 2016a). Table 26.3 illustrates typical student success strategies for a sample institution.

\section{Change Management Plan for Student Success}

Optimizing student success is one of the great change management challenges facing institutional leaders. Institutions need to embark on ongoing expeditions to leverage predictive learning analytics (and others) for student success. Table 26.4 illustrates the sort of overarching change management plan that enables institutions to turn student success initiatives into institutional strategies that will transform culture, processes, and practices over time.

Effective change management interventions for student success can accelerate the rate at which institutions embed learning analytics-driven interventions into the organization. They can focus the attention of leadership at all levels on the importance of changing culture and communication.

\section{INSTRUCTIVE FAILURES AND SUCCESS STORIES}

What can be learned from examining institutions that have been embedding learning analytics into their processes, practices, and student success strategies? Let's use two lenses: "instructive failures" and "success stories."

\section{Instructive Failures}

What constitutes an instructive failure in the embedding and leveraging of analytics in institutional processes and culture? In most cases, failure does not mean complete and abject rejection of embedded learning analytics. Rather, it means failure to overcome orga-

Table 26.3. Crafting Active Strategies for Student Success

\begin{tabular}{|c|c|}
\hline Strategies & Description \\
\hline $\begin{array}{l}\text { Strategy \# 1: Develop Unified Data, Infor- } \\
\text { mation, and Predictive Learning Analytics } \\
\text { for Student Success }\end{array}$ & $\begin{array}{l}\text { Strategy \# } 1 \text { should focus on improving the data, information, and analytics capacity of the } \\
\text { institution. The individual goals under this strategy should focus on technology infrastructure; } \\
\text { policies, processes, and practices; and skills and talent development as indicated in Table } 26.2 \text {. } \\
\text { These goals should establish metrics and stretch targets for the five-year planning timeframe. }\end{array}$ \\
\hline $\begin{array}{l}\text { Strategy \#2: Integrate Planning, Re- } \\
\text { sourcing, Execution, and Communication } \\
\text { (PREC) for Student Success }\end{array}$ & $\begin{array}{l}\text { Practical experience has shown that institutions are plagued by fragmented processes and prac- } \\
\text { tices for planning, resourcing, executing, and communicating (PREC) student success initiatives. } \\
\text { Strategy \#2 should establish the goal of integrating PREC activities across the seven dimensions } \\
\text { of student success optimization: 1) managing the pipeline; 2) eliminating bottlenecks, copying } \\
\text { best practices; 3) enabling dynamic intervention, 4) enhancing iPASS; } 5 \text { ) leveraging next gen } \\
\text { learning and learning analytics; } 6 \text { ) achieving unified data; and 7) extending the definition of stu- } \\
\text { dent success to include employability and career success (Baer \& Norris, 2016b). This strategy } \\
\text { should establish metrics for improving practice along these seven dimensions and set stretch } \\
\text { goals. }\end{array}$ \\
\hline $\begin{array}{l}\text { Strategy \#3: Advance Individual Planning } \\
\text { and Advising for Student Success } \\
\text { (iPASS) }\end{array}$ & $\begin{array}{l}\text { iPASS is one of the game changers in student success. Strategy \#3 should focus on enhancing } \\
\text { the institution's current iPASS platform and practices. Goals should focus on integrating iPASS } \\
\text { with other platforms and analytics and with new approaches to learning interventions such } \\
\text { as personalized learning. Dramatically increasing the number, effectiveness, and targeting of } \\
\text { interventions should be a goal and metric. See Seven Things You Should Know About IPAS and } \\
\text { iPASS Grant Recipients. }\end{array}$ \\
\hline $\begin{array}{l}\text { Strategy \#4: Integrate Personalized } \\
\text { Learning and Competence Building into } \\
\text { Institutional Practice }\end{array}$ & $\begin{array}{l}\text { Personalized learning also promises to be a game changer. Strategy \#4 should focus on expand- } \\
\text { ing next gen learning innovations and taking them to scale across the institution. Introducing } \\
\text { competence building will be an important differentiator for the institution in the longer term. }\end{array}$ \\
\hline $\begin{array}{l}\text { Strategy \#5: Integrate Employability and } \\
\text { Workforce Data into Institutional Practice }\end{array}$ & $\begin{array}{l}\text { Strategy \#5 has a longer time frame than the others but it is likely to have important long-term } \\
\text { impacts. Getting started now will enable institutions to establish a competitive advantage. }\end{array}$ \\
\hline
\end{tabular}


I. Aligning the student success initiatives to institutional context

Collaboration: What sort of guiding coalition and campus teams are needed?

Culture: How can you align with institutional culture and intentionally change it over time?

Leadership: What role does leadership at all levels play in optimizing student success?

The institution forms a guiding coalition to oversee student success. This is a cross-disciplinary team that evolved from integrated planning for student success. The guiding coalition will serve as the steward/shepherd for the execution of the student success strategy.

In assessing its current organizational culture and context, the institution assesses its institutional culture for using data, information, and analytics to support student success. They also assess the current capacity and culture to engage all staff and faculty in student success efforts. They express their intent to move from a culture of reporting to a culture of evidence-based decision making and more aggressive interventions to build student success.

The institution's assessments establish that executive leadership is critical to building support for student success efforts, mobilizing energies, and building commitment. This is true at all stages of student success development. To achieve a highly functional state of student success achievement, leadership and talent must be developed at all levels of the organization.

\section{Connecting new student success initiatives to current student success efforts and data systems/analytics}

Integration: How can we "connect the dots" linking all student success initiatives?

To overcome the extreme fragmentation in its student success processes, the institution participates in integrated strategic planning for student success. Utilizing the rubrics, strategies, and expedition maps emerging from this process, the guiding coalition will assure the integration and alignment of resourcing, execution, and communication.

Data and Analytics Resources: What current resources are available and what additional ones are needed?

The initial gap analysis of investment in student success initiatives and data, information, and analytics, in particular, reveal a performance gap and actions to fill the gap. Leveraging analytics is critical to optimizing student success and to monitoring and setting stretch goals.

Responsibility: Who is responsible for the elements of optimizing student success?

The initial assessment yields a mapping of responsibilities for all aspects of student success optimization. This mapping then guides the formation, composition, and functioning of the guiding coalition.

III. Engaging faculty, staff, and other stakeholders to change their perspectives and practices, and enable process and practice improvement

Communication: Who are the key stakeholders and what kind of communication plan is needed?

Talent Development: What sort of talent development is needed to develop faculty and staff?

Demonstrate Success: How do we achieve early victories and demonstrate value-added and ROI?
The initial integrated planning assessment yields a mapping of the stakeholders for student success activities. This mapping has quided the formation, composition, and functioning of the guiding coalition

Talent development needs emerge from innovation and expeditionary strategy crafting work shops. These drive the skills development elements of the five strategies.

So-called "low-hanging fruit" are identified throughout the innovation and expeditionary strategy crafting workshops. These elements are then regularly updated and utilized by the guiding coalition. nizational inertia to deploy and leverage embedded analytics in an effective manner that aggressively advances student success. Consider the following common examples:

- Many institutions make poor selection decisions in analytics tools, applications, and solutions. This may be due to who actually was responsible for purchasing the technology, better solutions that subsequently became available, how the campus systematically determined the integration of the tool, and ongoing investment in people and resources to launch and sustain the technologies. Even some of the most successful institutions have had to overcome poor selection decisions and/or migrate to better options that became available.

- Fundamentally, many institutions have not invested sufficiently in their data and information foundation. Their data are fragmented and cannot be combined across siloed databases; data are literally "hiding in plain sight." Achieving unified, accessible data requires persistent attention to data governance and is critical to leveraging analytics to achieve student success.

- Even institutions that have invested in excellent analytics packages often sub-optimize their use of these capabilities. By failing to prepare staff and faculty for how they can use these tools to identify at-risk behaviour and launch interventions, institutions sub-optimize their impact. Studies report that faculty believe they could be better instructors and students indicate that they could improve learning if they increased the use of the LMS (Dahlstrom, Brooks, \& Bichsel, 2014). All of the ERP LMS and analytics vendors report on this problem, but do not yet provide adequate talent development at the implementation stage to overcome it.

- Many institutions that do achieve advances in data, information, and analytics often fail to "connect the dots" by integrating all of the differ- 
ent student success interventions and activities across the institution. Failing to integrate planning, resourcing, execution, and communication (PREC) for student success will doom institutional efforts to sub-optimization.

Examples of similar instructive failure experiences can be found at most colleges and universities that are moving forward, but tentatively, in the effective deployment of embedded learning analytics. What can we learn from institutions that excel in leveraging embedded learning analytics?

\section{Success Stories: Institutions Getting it Right}

A small group of institutions have displayed the vision, leadership, and careful execution needed to leverage embedded analytics to advance student success. But even these leaders are far from done. They all report that student success analytics efforts are 5-7 year campaigns where the standards for success are continuously shifting upward. These long slogs require ongoing campus learning, flexibility, and research on what works and what doesn't. Consider the following success stories.

American Public University System (APUS) is an online, for-profit provider that has been a leader in using embedded analytics for over ten years. Analytics-driven interventions are part of their culture, and their student success innovations span the entire institution. Every week they evaluate and rank the risk level for all of their students and drive appropriate actions/interventions (Rees, 2016).

Arizona State University (ASU) has been a leader in the use of analytics-driven interventions in remedial education, advising, degree planning, and other vectors of student success over a long period. Their president is a nationally recognized champion in the strategic use of analytics. They have been pursuing adaptive courseware pilots, run as part of the Next Generation Courseware Challenge funded by the Bill \& Melinda Gates Foundation, which provide strong evidence of its positive effect on the learner experience. Important to the success was the development of data and dashboards that enhance interaction and communication between faculty and students (Johnson \& Thompson, 2016).

University of Maryland University College (UMUC) has developed an industry-leading capability to use predictive analytics to lead targeted learner interventions. Their enterprise-wide effort enjoys strong presidential leadership. UMUC is an industry leader in analyzing big data to identify appropriate and effective learner interventions, and the Center for Innovation in Learning and Student Success (CILSS) is providing research support for these efforts to improve student outcomes. The university is bringing learning analytics to bear on the full range of student concerns, from selecting courses to making the best use of study time. ${ }^{2}$

Sinclair Community College has been investing in data, information, and analytics for well over a decade. Its efforts began with merging three units to create a Business Intelligence Competency Center, developing a comprehensive data warehouse to provide "a single, unified version of the truth," and practice active data stewardship, data integration, and data quality. These supported one of the first iPASS systems and aggressive degree planning, which were used to make analytics-driven intervention in support of student success a key activity across the institution (Moore, 2009). ${ }^{3}$

Colorado State University (CSU) has achieved significant increases in graduation rates and has all but eliminated the minority achievement gap over the past decade. Its strategy for student success calls for even greater gains over the next decade. CSU has enhanced its performance by making student success a recognized institutional strategy and has organized around that principle. They have a VP for Student Success and have mobilized an active network of faculty, staff, and others to improve academic, co-curricular, and other student experiences. Student success is accepted as being everyone's job. Data, information, and analytics have been key elements of the university's progress and are embedded in the highly integrated student success processes and practices (Lamborn \& Thayer, 2014).

Even the most advanced institutions do not believe they are done. New tools and practices keep raising the bar for student success analytics and practices. The best is yet to come.

\section{CONCLUSION}

As institutions seek to unleash the transformative power of learning analytics, they must be prepared for an extended campaign, punctuated by carefully planned victories and demonstrations of how leveraging analytics can enhance student success. Institutional strategy for student success is an emergent pattern of focused, consistent behaviour over time, responding to changing environmental conditions and new trends as they present themselves (Mintzberg et al., 1998, p. 5). The key to optimizing student success is an aggressive combination of leadership, active strategy, and change management, as illustrated in

${ }^{2}$ See Predictive Analytics Leads to Targeted Learner Interventions: http://www.umuc.edu/innovatelearning/initiatives/analytics.cfm and Predictive Analytics for Student Success: Developing Data-Driven Predictive Models of Student Success: http://www.umuc edu/visitors/about/ipra/upload/developing-data-driven-predictive-models-of-student-success-final.pdf

${ }^{3}$ See My Academic Plan: https://www.sinclair.edu/services/basics/academic-advising/my-academic-plan-map/ 
Figure 26.2.

\section{Leadership}

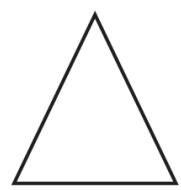

Active Strategy

Change Management

Figure 26.2. Unleashing the transformative power of learning analytics.

To prepare for and leverage these developments, the faculty and administration should coordinate and focus their activities in distinctive ways, using research-based decision making and developing their own site-specific best practices.

\section{Individual Faculty Seeking to Become Accomplished Learning Analytics Practi- tioners}

Learning-analytics-based projects are not just technical innovations; they are adaptive innovations, requiring active engagement of all participants in co-creating the design and outcomes (Heifetz, 2014). Individual faculty should realize that the introduction of learning analytics tools challenge some of the basic, traditional cultures of institutions. They will require new, more collaborative approaches to innovation and to the pervasive use of shared, performance-based evidence. Building skills in learning analytics should be a highly strategic move for faculty - if such skills are recognized, valued, and rewarded by academic leadership.

Communities of learning analytics practice will likely emerge and draw individual faculty into collaborations beyond their academic departments. This will also require a more comprehensive understanding and use of learning and course management systems. ECAR's report on The Current Ecosystem of Learning Management Systems in Higher Education: Student, Faculty, and IT Perspectives (Dahlstrom et al., 2014) concluded from surveys that:

- $\quad$ Faculty and students value the LMS as an enhancement to teaching and learning experiences, but relatively few use the full capacity of the systems.

- User satisfaction is highest for basic LMS features and lowest for collaboration and engagement features.

- $\quad$ Faculty say they could be more effective instructors and students could be better students with more skilled use of the LMS.
- Students and faculty want the LMS to have enhanced features and operational functions; be personalized; and use analytics to enhance learning outcomes.

In addition, faculty must understand the emerging features of next generation digital learning environments (Brown, Dehoney, \& Millichap, 2015). These new, cloud-based platforms will be loosely coupled and will enable better integration of analytics, varying modes of learning, learning objects, and mobile learn apps.

\section{Institutional Faculty and Staff Involved with Student Success Initiatives}

Large-scale student success initiatives are creating new opportunities for individual faculty and staff to participate in cross-department and cross-function collaborations. These efforts will dramatically increase the number and effectiveness of interventions to enhance student success. Greater understanding of what interventions are working for which students will be critical. Institutions can expand the return on investments in interventions when they target the initiatives to students who will most benefit in a timely manner (Baer \& Norris, 2016b). There are several approaches to improving student success initiatives including a more focused effort through a student success team. This approach brings multiple institutional players together to better integrate and collaborate on behalf of services to students. Service providers can better leverage institutional resources, jointly reviewing and selecting technologies to support services and providing ongoing evaluation of what works. ${ }^{4}$

More specific to learning analytics is understanding the following: 1) metrics to measure learning, 2) availability, use, and training on tools such as learning management systems and course management systems, 3) an inventory of interventions or actions available as risky learning behaviour is identified, 4) clear policies and practices supported by data governance, and 5) ongoing linkages to skills, competencies, and workforce.

\section{Institutional Leaders and Policy Makers Seeking to Unleash the Transformative Power of Learning Analytics}

Institutional leadership must actively discharge their responsibility to craft the institutional strategies and change management plans to enhance student success that will ultimately unleash the power of learning analytics. In the process, they will progressively transform the organizational culture and context. These efforts will require a dynamic combination of leadership,

\footnotetext{
${ }^{4}$ See Elevation through Collaboration: Successful Interventions for Students on Probation: http://www.nacada.ksu.edu/Resources / Academic-Advising-Today/View-Articles/Elevation-through-Collaboration-Successful-Interventions-for-Students-on-Probation. aspx Hints on how to scale initiatives can be found in Scaling Community College Interventions: http://www.publicagenda.org/files/ CuttingEdge2.pdf
} 
active strategy, and change management to achieve their potential. The details are critical in policy and practice development around learning analytics. It is apparent in conversations with campuses that interpretations about data privacy and protection can in fact hinder the adoption and deployment of learning analytics. Institutions must deal with the ecosystem of ethical issues and policy changes in order to 1) insure proper collection and use of data, 2) protect individual rights concerning the use of data, and 3) support the ethical and legal use of data within the institution. To this end, the purpose and boundaries regarding the use of learning analytics should be well defined and visible. Students should be engaged as active agents in the implementation of learning analytics (e.g., informed consent, personalized learning paths, and interventions.) Slade identifies gaps around policy for use of learning analytics in the following areas: 1) moral purpose; 2) purpose and boundaries; 3) informed consent; 4) collection, analyses, access to, and storage of data; 5) students as active agents, and 6) labelling and stereotyping (Slade, n.d.).

\section{Employers and Policy Makers Provide Ef- fective Linkages to Career and Workforce Knowledge}

The addition of competence, career, and workforce knowledge to the information base supporting student success efforts will be a major breakthrough. It will stimulate new approaches and practices and support the emergence of highly effective iPASS in institutions. These linkages are continuing to be developed. Some fields are clearly mandating certification and use evidence of skill competencies. Advances in the field are now enabling match ups of job or career needs with competencies demonstrated.

Put simply, learning analytics are destined to be instrumental in the transformation of how we prepare for and live our lives, guided and sustained by perpetual learning. They will surely impact the transformation of many aspects of colleges, universities, and other learning enterprises - and faculty, staff, students, and others who make them work.

\section{REFERENCES}

Ali, N., Rajan, R., \& Ratliff, G. (2016, March 7). How personalized learning unlocks student success. Educause Review. http://er.educause.edu/articles/2016/3/how-personalized-learning-unlocks-student-success

Baer, L., \& Norris, D. M. (2015, October 23). What every leader needs to know about student success analytics: Civitas White Paper. https://www.civitaslearningspace.com/what-every-leader-needs-to-know-aboutstudent-success-analytics/

Baer, L., \& Norris, D. M. (2016a). A call to action for student success analytics: Optimizing student success should be institutional strategy \#1. https://www.civitaslearningspace.com/StudentSuccess/2016/05/18/ call-action-student-success-analytics /

Baer, L., \& Norris, D. M. (2016b). SCUP annual conference workshop: Optimizing student success should be institutional strategy \#1. Society for College and University Planning (SCUP-51), 9-13 July 2016, Vancouver, BC, Canada.

Brown, M., Dehoney, J., \& Millichap, N. (2015, June 22). What's next for the LMS? Educause Review. http:// er.educause.edu/ero/article/whats-next-lms.

Craig, R., \& Williams, A. (2015, August 17). Data, technology, and the great unbundling of higher education. Educause Review. http://er.educause.edu/articles/2015/8/data-technology-and-the-great-unbundling-of-higher-education

Dahlstrom, E. (2016, August 22). Moving the red queen forward: Maturing analytics capabilities in higher education. Educause Review. http://er.educause.edu/articles/2016/8/moving-the-red-queen-forward-maturing-analytics-capabilities-in-higher-education

Dahlstrom, E., Brooks, D. C., \& Bichsel, J. (2014). The Current Ecosystem of Learning Management Systems in Higher Education: Student, Faculty, IT Perspectives. ECAR. https://net.educause.edu/ir/library/pdf/ ers1414.pdf

ECAR (2015, October 7). The predictive learning analytics revolution: Leveraging learning data for student success. ECAR Working Group Paper. https://library.educause.edu/ /media/files/library/2015/10/ewg1510pdf.pdf 
Heifetz, R. A. (2014, February 18). Adaptive and technical change. http://www.davidlose.net/2014/02/adaptive-and-technical-change/

Hilton, J. (2014, September 15). Enter UNIZIN. Educause Review. http://er.educause.edu/articles/2014/9/enter-unizin

Johnson, D., \& Thompson, J. (2016, February 2). Adaptive Courseware at ASU. https://events.educause.edu/ eli/annual-meeting/2016

Karp, M. M., \& Fletcher, J. (2014, May). Adopting new technologies for student success: A readiness framework. http://ccrc.tc.columbia.edu/publications/adopting-new-technologies-for-student-success.html

Lamborn, A., \& Thayer, P. (2014, June 17). Colorado State University Student Success Initiatives: What's Been Achieved; What's Next. Enrollment and Access Division Retreat.

Little, R., Whitmer, J., Baron, J., Rocchio, R., Arnold, K., Bayer, I., Brooks, C., \& Shehata, S. (2015, October 7). The predictive learning analytics revolution: Leveraging learning data for student success. ECAR Working Group Paper. https://library.educause.edu/resources/2015/10/the-predictive-learning-analytics-revolution-leveraging-learning-data-for-student-success

Mintzberg, H., Ahlstrand, B., \& Lampel, J. (1998). Strategy Safari: A guided tour through the wilds of strategic management. New York: The Free Press.

Miyares, J., \& Catalano, D. (2016, August 22). Institutional analytics is hard work: A five-year journey. Educause Review. http://er.educause.edu/articles/2016/8/institutional-analytics-is-hard-work-a-five-year-journey

Moore, K. (2009, November). Best practices in building analytics capacity. Action Analytics Symposium.

Norris, D., \& Baer, L. (2013). A toolkit for building organizational capacity for analytics. Strategic Initiatives, Inc.

Norris, D., \& Keehn, A. K. (2003, October 31). IT Planning: Cultivating innovation and value. Campus Technology. https://campustechnology.com/Articles/2003/10/IT-Planning-Cultivating-Innovation-and-Value.aspx

Rees, J. (2016, August 30). Adoption leads to outcomes at American Public University System. Civitas Learning Space. https://www.civitaslearningspace.com/adoption-leads-outcomes-american-public-university-system/

Sclater, N., Peasgood, A., \& Mullan, J. (2016, April 19). Learning analytics in higher education: A review of UK and international practice. https://www.jisc.ac.uk/reports/learning-analytics-in-higher-education

Slade, S. (n.d.). Learning analytics: Ethical issues and policy changes. The Open University (PowerPoint presentation). https://www.heacademy.ac.uk/system/files/resources/5_11_2_nano.pdf

Weiss, M. R. (2014, November 10). Got skills? Why online competency-based education is the disruptive innovation for higher education. Educause Review. http://er.educause.edu/articles/2014/11/ got-skills-why-online-competencybased-education-is-the-disruptive-innovation-for-higher-education

Yanosky, R., \& Brooks, D. C. (2013, August 30). Integrated planning and advising services (IPAS) research. Educause. https://library.educause.edu/resources/2013/8/integrated-planning-and-advising-services-ipas-research 